\title{
RESISTENCIA POLITICA POPULAR EN CHILE: 1978-1984
}

\author{
POPULAR POLITICAL RESISTENCE IN CHILE: 1978-1984
}

\author{
Robinson Silva Hidalgo* \\ RSILVAHIDALGO@YAHOO.ES
}

\section{RESUMEN}

Este artículo presenta las diferentes formas de violencia política desarrolladas por el Movimiento de Izquierda Revolucionaria (MIR), durante el período de refundación del capitalismo chileno, ocurrido en la dictadura de Augusto Pinochet Ugarte. Se diferencia entre formas de violencia política de alta y de baja intensidad. En el ejercicio de esta violencia, se estudia la participación tanto de la fuerza central del MIR, como de las Milicias de Resistencia Popular. Además, se presentan las motivaciones políticas del acto de violencia ejercido por este sector de la izquierda chilena. Finalmente, se revisan los elementos constitutivos de las distintas acciones de violencia política, en el marco de la reconstrucción del movimiento social iniciado a principios de la década de $\operatorname{los} 80$.

Palabras claves: Augusto Pinochet, movimiento social antidictatorial, resistencia popular, violencia política.

\begin{abstract}
This article presents the different ways of political violence developed by the Revolutionary Left Movement (MIR) during the period of refoundation of Chilean capitalism, occurred under the dictatorship of Augusto Pinochet Ugarte. It distinguishes between high and low intensity political violence. It studies the participation of both the central force of the MIR and the Popular Resistance Militia in the exercise of this violence. Furthermore, it presents the political motivations behind the violence exerted by the Chilean left. Finally, it reviews the constituting elements of the different actions of political violence, in the framework of the reconstruction of the social movement that started during the early eighties.
\end{abstract}

Keywords: Augusto Pinochet, antidictatorship social movement, popular resistance, political violence.

\section{INTRODUCCION AL MOVIMIENTO SOCIAL ANTIDICTATORIAL}

Una buena premisa para comenzar tiene relación con el movimiento social y político de los ochenta en Chile. Si bien este tema tiene múltiples visiones de corte académico, quisiéramos dar una idea de lo que, creemos, significa este fenómeno.

Un movimiento de este tipo es la expresión de las transformaciones que vive una sociedad, funda nuevas relaciones entre los actores sociales y conforma una nueva estructura en el Estado'. Si bien esto explica genéricamente el proceso, no debe olvidarse que las motivaciones conducentes a estas transformaciones son necesarias de medir y pesar a razón de evaluarlas políticamente como armas de la mediación que reubica a los actores en la nueva estructura construida.

Para comenzar debemos remontarnos a las ideas de uno de los más importantes pensadores de los movimientos sociales, Alain Touraine. El sociólogo francés construye su noción de movimiento social al fragor de la ola de protestas de la década del sesenta en el mundo entero. Desde allí que su mirada parte de la crítica a las estructuras y pone de relieve al actor social sujeto constituyente de estos movimientos. Esta concepción incorpora la idea de que aquellos sujetos sociales logran construir un sentido en su adscripción a estos movimientos.

*Magíster en Historia por la Universidad de Concepción.

' Garretón, Manuel. "Del autoritarismo a la democracia política. ¿Una transición a reinventar?", Documentos de Trabajo, FLACSO, Santiago, No 5, 1990, p.1. 
...la idea de movimiento social, es decir, de conflicto entre dos categorías en lucha por la dirección y la utilización social de las principales orientaciones culturales de una sociedad, lo que yo nombro sus modelos culturales: conocimiento, proyección, principios éticos, y cuyo conjunto forma su historici$\mathrm{dad}^{2}$.

Esta definición que podemos acordarla sin problemas para el período histórico que el país vivió en los años de la Unidad Popular y anteriores, conforma un vínculo muy estrecho con una visión de lo político y social muy acendrada en la izquierda latinoamericana de esos años.

En ese marco es que partidos como el MIR concibieron estrategias y políticas para redefinir las relaciones entre el "pueblo" y el Estado. Esta intención se desarrolla en una sociedad fuertemente marcada por los procesos de modernidad y modernización que el siglo veinte le impuso. Con el devenir de los sucesos políticos que Chile sufrió quedó en evidencia que ese proceso "cultural", como lo llama Touraine, era débil y poco probable de ser zanjado con éxito.

En medio de esta problemática, Touraine coloca al sujeto como centro del movimiento que desarrolla cambios, el actor social como él lo llama; se define en cuanto encuentra un conflicto que lo reclama, a medio camino entre el sujeto y la experiencia social. De este modo, comprendemos que la constitución de sujetos en actores sociales es una de las premisas que debemos seguir para encontrar quiénes son éstos en el desarrollo histórico del proceso que observamos.

Hasta aquí entendemos que un movimiento social es un proyecto cultural y un conflicto social ${ }^{3}$, situándonos en la disyuntiva de crear categorías históricas en virtud de coyunturas dadas por estos engranajes convertidos en matrices para la comprensión histórica. Necesitamos acercarnos a referencias más específicas al tiempo que estudiamos; necesitamos mayor cercanía con la realidad del fenómeno que nos interesa.

La teoría convino en repensar el concepto de movimiento social a la luz de los resultados de estos procesos en el mundo, y particularmente en Latinoamérica esto se hizo muy claro. La sociología volvería sobre sus fueros para retomar el debate y recomponer ideas y reflexiones. Ahora Anthony Giddens propondría otros formatos de movimiento social, basado en los fenómenos de modernidad-posmodernidad que se comenzaron a discutir desde los años ochenta.

En lo referente a la concepción de movimientos sociales que se maneja por parte de Giddens se pueden encontrar diversas tipificaciones de éstos, desde el fundacional movimiento obrero, que inicia la participación de las clases populares en la sociedad moderna, hasta los movimientos contemporáneos signados por demandas ligadas a la subjetividad con las que se construyen las relaciones en el capitalismo mundial o globalización, como también se le ha llamado.

Se ha propuesto como forma de explicación del surgimiento de movimientos sociales la idea de ciclos de protesta. Otros los definen como construcción de identidad colectiva a través de procesos de interacción nosotros creemos que no hay exclusión entre estas interpretaciones, pensando en el caso chileno del último período dictatorial.

De este modo ampliamos el marco de comprensión sobre los significados que el movimiento social tiene para el devenir histórico de los procesos.

La integración de ambos enfoques puede prevenir la tendencia a dejar de lado determinadas características de la organización social que son básicas para entender cómo son percibidos y definidos los problemas sociales por parte de los movimientos ${ }^{6}$.

\footnotetext{
${ }^{2}$ Touraine, Movimientos sociales hoy, 1990, pp. 12-13.

${ }^{3}$ Touraine lleva su definición de movimiento social al terreno de las ideologías y su desarrollo dialéctico, considerando a los movimientos como procesos en el marco de los cambios civilizatorios de mayor calado, propios de la discusión en torno a la modernidad. Si bien no podemos contrariar esta proposición, consideramos pertinente dibujar la constitución de movimientos sociales en el ámbito del tiempo corto, según las premisas de François Braudel.

${ }^{4}$ El sociólogo Anthony Giddens ha reflexionado acerca de la evolución de los movimientos sociales y su rol en la constitución de las sociedades modernas, desde su perspectiva podemos considerar la multiplicidad de elementos que se van agregando a estos movimientos, cuestión de lo cual el proceso chileno no es ajeno.

${ }^{3}$ Berger y Luckmann plantean que desde los sujetos estos procesos existen como una forma de proximidad que hace reconocer a otros como parte de la misma realidad, cotidiana y directamente, para el caso del movimiento social esto crea lazos de pertenencia a una identidad colectiva, es por esto que ambos procesos van situados en el mismo fenómeno.

${ }^{6}$ Larraña, Enrique. La construcción de los movimientos sociales, 1999, p. 242.
}

Revista de Historia, año 17, vol. 17(2), 2007, pp. 53-69 
Sin duda para el caso chileno es oportuno extender esta precisión al terreno político, considerando que el movimiento social de la década de los años ochenta tiene su fundación en el problema político que surge del conflicto de legitimación que se vive en el país. Este movimiento se explica en un ciclo de protesta y genera una identidad colectiva en el entendido que lo político es el factor catalizador de estos enfoques.

Para Guattari y Negri la constitución de un movimiento es la constitución de un poder, de una forma de poder generado desde la subjetividad de los individuos convocados por romper el control del Estado y del capitalismo sobre sus vidas. Por ello los movimientos se construyen en virtud de objetivos muy diversos que se plantean en sí mismos y en función de ese control disciplinador externo a estas constituciones.

Las luchas internas y antagonistas contra la política de reestructuración reaccionaria se mueven, por un lado, contra el tejido represivo; por otro lado, en el interior de estos procesos de subjetivación como tensión unificadora y como perspectiva de autoliberación...?

Bajo este marco explicativo, las acciones de movilización no se desarrollan por las condiciones que imponen las relaciones de producción o los cambios sociales estructurales. Lo anterior no significa que sea posible tipificar el movimiento social chileno de los ochenta en este paradigma o en las explicaciones definidas por la identidad o la cultura.

Los movimientos sociales, entonces, complejizan las estructuras de las sociedades y permiten desatar fuerzas desde los individuos, poniendo sus temas en la política y utilizando los medios más diversos para la lucha contra el control del Estado, cuestión que se discute dentro del mismo movimiento. En ese camino es que tanto las protestas como las identidades forjaron los temas y los métodos por los cuales el movimiento social se resignificó, ahora en el marco de la refundación del capitalismo que propuso la dictadura desde 1978. "Lo novedoso de los años ochenta es el surgimiento de una acción colectiva más autónoma y no heterónoma respecto de los partidos políticos y el movimiento obrero organizado...".

El punto central en este debate está en la acción colectiva. Esta es la definición que nos compromete con la idea de referir un movimiento social antidictatorial, con ello se concreta una experiencia histórica que profundiza en el devenir del período que estudiamos, más allá de cualquier calificación sobre este agenciamiento, tenemos actores sociales en movilización, pudiendo historiar al mismo, esto es evidente en aspectos como la movilización de mujeres, jóvenes o el movimiento cultural.

Es en una explicación como la descrita que el movimiento social antidictatorial, en cuanto gatillado por lo político, se afirma en objetivos signados por la autonomía en su control y desarrollo de una sola agrupación partidaria, obligando a la unidad de todos los opositores, cuestión que es controversial para el período posterior al estudiado aquí; pero que es válido para la etapa de surgimiento de este movimiento.

Cabe señalar al llegar a este punto que la relación violencia política y movimiento social se funda en los grados existentes entre ambos en virtud de su legitimidad; en cuánto y cómo el movimiento social popular en oposición al régimen militar cobija, alienta o rechaza la acción de violencia, hasta dónde la tolera o qué tipo de violencia es capaz de concebir como necesaria u oportuna. Si bien estos problemas pudieran ser tema para otra investigación, creemos poder enfrentar algunas reflexiones desde el ejercicio de violencia política estudiado aquí.

El fenómeno chileno de la década de los ochenta consideró el cambio en la estructura productiva del país, priorizando las exportaciones de materias primas, haciendo desaparecer en su devenir sujetos históricos como el proletario industrial y minero; por otra parte se privilegia el sector financiero, haciendo de la banca el guardián de la economía nacional frente a la crisis de $1982^{\circ}$.

El movimiento antidictatorial se potencia ante esta problemática. Pero las tradicionales formas de lucha de la izquierda se estrellan frente a problemas nuevos en un contexto nuevo: sin libertad política es imposible pedir mejores salarios o mejores condiciones laborales. Así, el movimiento se centrará en resolver la traba política arguyendo el problema económico sin que éste tenga mayor desarrollo como tema en el debate. La economía como experiencia práctica y teórica en este período contextualiza la lucha antidictatorial.

\footnotetext{
' Guattari, Félix y Negri, Antonio. Las verdades nómadas \& general intellect, poder constituyente, comunismo, $1999, \mathrm{pp} .50-51$.

${ }^{8}$ Zamorano, Raúl. "Dilemas políticos sobre los movimientos sociales. El accionar colectivo de los sectores populares en el Chile de los años ochenta", Revista mexicana de sociología, México D. F, Vol. 61, № 3, 1999. p. 204.

${ }^{9}$ Guillaudat y Mouterde. Los movimientos sociales en Chile, 1973-1993.1998, p.128. Los autores establecen esta tesis como la centralidad de los cambios estructurales que vive el país en el período.
} 
"Durante el proceso de reinstauración del poder de la gran fiera corrió la sangre y, luego de algunos años, hubo lucha; lucha que asumió fuerza social antropológica, utilizando el pueblo primitivo instrumentos de piedra y utensilios primarios de la cocina casera... ${ }^{10}$.

En particular, aunque no exclusivamente, han sido los historiadores chilenos quienes intentan explicarse los alcances y características del movimiento social en este período. Para ello es que las teorizaciones consideran un fuerte componente en lo político, pero también rescatan las dimensiones sociológicas del fenómeno, dentro de ello la utilización de la violencia como forma de respuesta.

Se ha construido incluso un concepto para explicar el fenómeno colectivo en Chile, no sólo para el período, sino para comprender las anomalías que se han producido históricamente cada vez que los diversos colectivos han constituido un poder. A esto se le ha llamado "movimiento social popular" y corresponde a una forma de entender a los sujetos en movimiento por autoconstituirse en ciudadanos".

Para el historiador Julio Pinto, la idea de movimiento en Chile se encontraría predominada por el referente de clase. Es por ello que definimos al movimiento social como popular, en desmedro de otras posibilidades como étnico o religioso entre otros. El "pueblo" tiene una constitución histórica en base a sus experiencias en el devenir del tiempo en que se ha desarrollado como un sujeto histórico.

En consideración a la idea de movimiento y en base a esa experiencia popular en la historia de Chile, permite definir el concepto de movimiento social desde la historiografía. El mismo Julio Pinto nos acerca al concepto de movimiento social que consideraremos para el período estudiado en esta investigación. "En el caso específico de los actores populares, se supone también que esta movilización se enmarca en una realidad que las más de las veces se aparece como problemática, a menudo decididamente adversa"'12.

Es necesario aclarar que este tipo de agenciamiento sociohistórico es el que constituirá la base de las jornadas de protesta que darán carne y situarán al movimiento social antidictatorial, es decir, estará cruzado por su carácter popular y centrado en las dimensiones de la pobreza y de las relaciones opresivas ejercidas sobre las clases populares por los agentes del poder, radicados en el Estado.

La constitución del movimiento social en el Chile dictatorial obviamente pasa por un factor político muy gravitante: la derrota de la dictadura. Este elemento se tornará vital a la hora de considerar la organización y desarrollo de este movimiento. Difícilmente se entenderá el paso de los "viejos" a los "nuevos" movimientos sociales $^{13}$, cuando la importancia está puesta en el debate y la lucha política; además cuando ésta es negada. Este elemento es controversial desde la perspectiva de los historiadores de la nueva historia social que creen en este tránsito.

$\mathrm{Al}$ elemento anterior debemos agregar la fuerte transformación económica y social de un país en pleno proceso de refundación del capitalismo. El modelo neoliberal propone un verdadero desafío para los autoconstituidos en movimiento social. Desde ahí comprendemos que se multiplican las dimensiones del movimiento social enfrentado a una confrontación propia de su historicidad, es decir, popular; pero en el marco de la lucha política y en medio de un cambio estructural de la sociedad, la instalación del neoliberalismo.

Para desarrollar de mejor forma este proceso, presentaremos los aspectos señalados por separado para ubicar sus propios debates y caracterizar su desarrollo. La confrontación política por una parte y la instalación de una nueva estructura económica y social. Planteado así, el movimiento social explica su identidad histórica específica.

\footnotetext{
${ }^{10}$ Illanes, María Angélica. "Marginalización y des-marginalización del movimiento popular". Proposiciones, Ediciones SUR, N²4, 1994, p. 224.

"A través de la extensa obra de Gabriel Salazar y de muchos otros historiadores de esa generación podemos encontrar el interés por desarrollar modelos explicativos a esta configuración llamada movimiento social popular, con ello queda claro la importancia central que tiene comprender los fenómenos que gatillan la aparición de movimientos en sus expresiones más fulgurantes como lo fueron las protestas que auguran el fin de la dictadura.

${ }_{12}^{12}$ Pinto, Julio. "Movimiento social popular: ¿hacia una barbarie con recuerdos?" Proposiciones, Ediciones SUR, N 24,1994 p. 215.

${ }^{13}$ Esta transición de movimientos "viejos a los nuevos" es la que se desarrolla mundialmente en la década de los ochenta, cuando Chile vive la construcción de un movimiento de las características señaladas aquí. Los sociólogos como Giddens y Larraña centran sus análisis en esta temática.
}

Revista de Historia, año 17, vol. 17(2), 2007, pp. 53-69 


\section{ILEGITIMIDAD DE LA REPRESENTACION POLITICA DICTATORIAL}

El debate sobre la legitimidad de una representación política, en el caso del Chile dictatorial, pasa por un análisis acerca del Estado y su nueva institucionalidad, además de los dispositivos adoptados para llevar adelante los cambios estructurales. Se estima en la actualidad que la merma será resentida específicamente por los ciudadanos, imposibilitados desde entonces de generar poder sobre los grupos que acceden al Estado para decidir con y para ellos.

La "construcción del Estado" ha sido, más a menudo que no, un proceso en que los "poderes fácticos" han avasallado a la ciudadanía. Lo que implica avasallar la legitimidad - en tanto valor incorporado al sistema por la acción constructiva de la sociedad civil-... ${ }^{14}$.

Es la sociedad civil la que reconocerá la ilegitimidad de la dictadura en la visión de los partidos de izquierda. Y es a través de la movilización social que esto tomará cuerpo y construirá alternativas para la situación política chilena. La preocupación hacia 1980 será entonces el tema del nuevo orden institucional que el régimen intenta imponer por medio de la Constitución Política y su validación por parte de los chilenos.

El concepto que se acuña en el gobierno para lograr la aceptación de este nuevo orden es el de "unidad nacional". Esta idea niega cualquier posibilidad a las ideas políticas de izquierda. Para los partidarios del régimen se deben concentrar las tareas de preservar un orden estático y de permanente obediencia.

La inmovilización social se instauró como la característica más palpable de la vida ciudadana chilena. Luego de un período tan álgido en manifestaciones como lo fue la Unidad Popular, el gobierno de la Junta Militar traería medidas propias del Estado de excepción como el toque de queda o la prohibición de reunión y asociación que redundarían en la anulación de la movilización social y política, propia de la cultura chilena del siglo $\mathrm{XX}^{15}$.

Junto a la doctrina de seguridad nacional y la instauración de la hegemonía de un capitalismo fundado en el aparato financiero, lo que le da el carácter de neoliberal como se le ha bautizado, las políticas de contrainsurgencia se extienden a los movimientos sociales como el sindicalismo o las organizaciones populares de las ciudades, las más politizadas hasta septiembre de 1973.

En el período anterior al estudio aquí referido, 1973-1978, la represión ejerció su máximo poder y desarrollo. De esto sabemos mucho más en el último tiempo gracias a las investigaciones hechas desde hace algunos años por historiadores, periodistas y víctimas de la guerra sucia. Debe agregarse, con posterioridad, la verdad judicial y política que lentamente comienza a surgir, desarrollándose a través de los diversos mecanismos institucionales del Estado.

En el período comprendido entre 1983 y 1988 se gesta el desgaste y finalmente el término de la dictadura, producto de las movilizaciones sociales y populares desarrolladas en estos años, mediatizadas por el resurgimiento de los partidos de la izquierda y el centro político chileno. Esto viene a colocar las bases del sistema político y social que hoy tenemos y que la mayoría conviene en calificar como democracia pactada por gran parte de la academia chilena.

Es entre los años 1978 y 1983 en que se desarrolla la etapa más álgida del régimen dictatorial, en el quinquenio señalado se concreta el intento de construcción de un proyecto histórico y es también el momento en que la militancia de izquierda intenta rearticular sus diezmadas fuerzas para combatir a un enemigo poderoso y complejo de entender. El Movimiento de Resistencia Popular forma parte de esos intentos y creemos fundamental analizarlo históricamente.

En este período aparecen organismos de carácter público de línea radical en los espacios sociales en que el MIR apuesta para la reactivación de un movimiento masivo que se oponga a la Dictadura. Surgen organismos como el Comité de Defensa de los Derechos del Pueblo (CODEPU), la Coordinadora Nacional Sindical (CNS), el Comité de Defensa de Derechos de la Mujer (CODEM), la Coordinadora de Agrupaciones

\footnotetext{
${ }^{14}$ Salazar, Gabriel y Pinto, Julio: Historia contemporánea de Chile, volumen I, 1999, p. 16.

${ }^{15}$ Los estudios de historiadores como Gabriel Salazar, María Angélica Illanes o Sergio Grez, entre muchos otros, nos señalan que el movimiento social chileno en el siglo pasado tuvo una actividad permanente en el pensamiento de sí mismo ya sea en sus dimensiones políticas, económicas y sociales, ya sea desde el análisis de la cuestión social, el conflicto por la proletarización y el disciplinamiento o el desarrollo de un proyecto social popular. La historiografía tiene para Chile una instalación de problemas en cuanto su ser colectivo de nación y los conflictos que esto conlleva. La dictadura será el punto más alto de esta conflictividad y donde se posicionarán claramente los proyectos de las clases sociales del país.
} 
Poblacionales (COAPO), entre los de mayor desarrollo. Las manifestaciones sociales antidictatoriales se concentraron entre el grupo de pobladores, estudiantes y trabajadores, influyendo en las políticas de la izquierda socialista y comunista del país.

Los organismos surgidos en el ámbito sindical y en la lucha de Derechos Humanos concentrarán gran parte de sus argumentos en la idea de la ilegitimidad del régimen, siendo las concepciones que los llevaron a transversalizar su trabajo más allá de los partidos o grupos que les dieron origen.

Por otra parte, en organizaciones como el Comité de Defensa de los Derechos de la Mujer (CODEM) y la Coordinadora de Agrupaciones Poblacionales (COAPO) las temáticas se vinculaban a asuntos de largo aliento en la sociedad chilena. Los alcances ideológicos representaban más que un conflicto con la dictadura, una crítica al fondo mismo del capitalismo y la sociedad patriarcal construida en Chile desde los albores de su historia. Desde este punto de vista, tanto los problemas de género como los ligados a los de clase asumirán dimensiones distintas.

Por último, es indispensable insertar el análisis que de esta investigación resulte en el proceso político chileno en general. La construcción de la democracia y el modelo económico obedecen en parte a los acomodos de las fuerzas políticas en dictadura y su preeminencia definió qué tipo de modernizaciones y que tipo de amarres constituyen el resultado de las negociaciones que formarían el período noventista.

Las tesis, que afirmaban debía afianzarse la institucionalidad antes de emprender las reformas sociales que se estructuraron en el primer programa de la Concertación, provenían de la convicción de que la derrota del régimen pasaba por su cooptación en lo económico y político, es decir, administrar mejor el sistema que dejó la dictadura a cambio de garantizar la "paz social"; o sea, controlar la violencia política.

\section{Refundación capitalista}

El revisar los relatos históricos existentes sobre un período clandestino de un partido revolucionario resulta ciertamente fundamental para la reconstrucción de ese período, considerando el peso de esta fuerza en la política chilena y su rol en el proceso que llevaría a la transición política iniciada en 1988. Como la idea es despejar el peso de esta influencia en el movimiento político y social que se desarrolló en el Chile de los años ochenta, debemos recordar que en 1982 Chile vivió una de las crisis económicas más duras del siglo: la llamada "recesión" contribuyó a levantar un rechazo popular a la dictadura y el consiguiente renacimiento de los partidos políticos que capitalizaron en este período gran parte del descontento producido por la crisis.

El grupo exportador, la Sociedad Nacional de Agricultura, la Cámara de Comercio y las instituciones financieras internacionales deciden la refundación del capitalismo en Chile bajo los nuevos parámetros surgidos de la Escuela de Chicago. Todo esto incluyó libertad de precios y de comercio exterior, devaluación, modernización de la industria, privatización con cierre de empresas, desempleo, inversión de capital extranjero, monopolización de la riqueza, debilitamiento del Estado, entre otras características.

En otras palabras, el objetivo final apunta a que el Estado no disponga de ningún instrumento que pueda alterar la evolución óptima que genera el libre juego de las fuerzas del mercado; este tipo de entorno supuestamente estimula al sector privado a convertirse en motor dinámico del crecimiento ${ }^{16}$.

Se liberalizó el mercado de tierras, se desvió el crédito a los sectores privados en desmedro de las cooperativas, tecnificando su producción los primeros; se logró gran producción para la exportación y disminución para el consumo interno, no se regresó al latifundio porque se privilegio la creación de empresas capitalistas modernas, tanto en tecnología como en relaciones sociales.

La inflación se mantuvo en cifras récord $(375,9 \%, 1975 ; 211,9 \%, 1976)$ y fue aminorada con la política de shock que hizo caer la producción y el PIB, por esta razón subió el desempleo fuertemente y se contrajo la demanda interna, perjudicando especialmente a las manufacturas chilenas y a la construcción. La creación del Programa de Empleo Mínimo (PEM) y el Programa Ocupacional para Jefes de Hogar (POJH) para luchar contra el desempleo fue símbolo de la política dictatorial: 15 horas de trabajo por el tercio del salario mínimo. La productividad de los obreros del PEM era tres veces mayor que su salario, entonces, los más pobres aportaron al desarrollo de Chile en un régimen de explotación comparable a las primeras décadas del siglo XX.

${ }^{16}$ Meller, Patricio: Un siglo de economía política chilena (1890-1990), 1998, p. 183.

Revista de Historia, año 17, vol. 17(2), 2007, pp. 53-69 
Durante un tiempo la maniobra tuvo éxito; mientras se mantenían las altas tasas de desempleo, la destrucción-reestructuración de la economía chilena así como la puesta en práctica del Plan de Empleo Mínimo (PEM) fragilizaban y paralizaban las débiles capacidades de resistencia de la clase obrera ${ }^{17}$.

La problemática del empleo será uno de los temas centrales en las motivaciones argüidas por la Resistencia para el uso de la violencia política. La crisis económica y la refundación del proyecto económico liberal refuerzan estas ideas y serán parte del análisis permanente de los documentos partidarios así como de la prensa clandestina.

La crisis recesiva de 1982 repercutió en el ingente movimiento social contra la dictadura militar. Esta llevó a cabo una política represiva que no fue sopesada en su magnitud por la dirigencia política de oposición que combinó masividad y selectividad, con una oposición centrista que intentaba instalarse como interlocutor del oficialismo. Las posiciones más radicales centraron en el movimiento popular grandes expectativas, dada la ilegitimidad del régimen, tanto en lo político como en lo social.

Las políticas implementadas por el gobierno dictatorial desde 1978 marcan una nueva etapa en este régimen. En lo político se produce la institucionalización de la dictadura y se echan andar modernizaciones en el aparato económico del país. Para generar este nuevo cuadro se debió reprimir fuertemente el movimiento social, liderado históricamente por la izquierda.

...los primeros siete años del gobierno militar, entre el momento del golpe y 1980 , fecha en la cual el modelo neoliberal empieza a rendir frutos y se termina por consolidar con las denominadas "modernizaciones", particularmente la aprobación del Plan Laboral y el inicio de la Reforma Previsional que terminaron de desarmar el Estado Benefactor ${ }^{18}$.

Se configura desde este momento una dualidad en la forma de concebir el gobierno. Esta es una dictadura que tiene un proyecto. No es sólo la asonada para derrocar un gobierno socialista. Es un complejo entramado en que militares, empresarios y políticos de derecha consensúan la articulación de un proyecto que refunda el capitalismo bajo las premisas de la Escuela de Chicago, es decir, una profundización de las ideas del liberalismo económico.

Para el caso de la reforma previsional esta premisa se cumple totalmente, además de la necesidad de reformar el sistema, se hace en pos de los principios que se articulan desde la nueva economía.

Los fundamentos del régimen de pensiones basado en el reparto son la idea de contrato social y el principio de solidaridad, propias del Estado de compromiso. Su suplantación por un sistema de capitalización individual y de administración privada se inserta claramente en el proceso de los llamados "ajustes estructurales"...19.

El marco de fuerte represión social y política contradice las ideas liberales, pero es la condición necesaria que tiene que darse para imponer esta construcción. Los alcances de la lucha política se amplían a espacios ideológicos y es un desafío para la izquierda que, además de diezmada físicamente por la represión de los primeros años de la dictadura, se encuentra sitiada en sus espacios de organización y de pensamiento.

Por otra parte se debe señalar que esta crisis significó un cambio radical en la estructura de la sociedad chilena. El país no volvería a ser el mismo luego de las transformaciones hechas por el régimen bajo la égida de la influencia de la Escuela de Chicago. Se debe recordar que las recetas de Chicago provienen de la década del cincuenta y que influyó fuertemente entre los economistas de la Universidad Católica.

Esta influencia se hizo notar fuertemente en la reestructuración de las relaciones entre los empresarios, el Estado y los trabajadores. Se crea el nuevo Plan Laboral del gobierno, a cargo del economista José Piñera. Este plan restringe y limita los derechos laborales a los básicos, dando el control, en caso de conflictos, a los empresarios.

\footnotetext{
${ }^{17}$ Guillaudat y Mouterde. Op. cit., p. 107.

${ }^{18}$ Valdivia, V. El golpe después del golpe, Leigh vs. Pinochet. Lom. 2003, pp. 99-100.

${ }^{19}$ Elter, Doris. Sistema de A.F.P. chileno. Injusticia de un modelo, 1999, p. 92.
} 
El "mérito" del Plan Piñera radica en no escabullir los puntos del conflicto, pero de una manera sutil deja en el terreno de las empresas la posibilidad de decidir. Con esta política los trabajadores pueden afiliarse, pero compitiendo entre varios sindicatos; hubo derecho a huelga, pero sólo de sesenta días; se puede negociar colectivamente, pero excluyendo las tareas de "organizar, dirigir y administrar la empresa"20.

La respuesta del mundo sindical se fraguaba desde una incipiente movilización. Pero el movimiento social no existe por sí mismo en estos años. Se configura en movilizaciones específicas de ciertos sectores que comienzan a aglutinarse en torno a la oposición al régimen. Así, el 7 de enero de 1977 se crea la Coordinadora Nacional Sindical, ante la imposibilidad de refundar la Central Unica de Trabajadores, CUT.

Una de las fuerzas más relevantes del movimiento social es el sindicalismo, de gran peso en Chile. Pese a estar proscrito en una de sus expresiones claves, el vínculo con los partidos políticos. Frente a la dura legislación instalada con el nuevo Código del Trabajo, el sindicalismo se reactiva, manifestándose paulatinamente desde 1978.

El entramado de agrupaciones sindicales tiene gran relevancia para la Resistencia. Es en las luchas de los trabajadores y el rechazo al "Plan Piñera" que se articulan acciones de violencia miliciana para reforzar las movilizaciones laborales que van tomando cuerpo en la medida que avanzan los años de este período.

El grito: “¡Chile, escucha, PANAL está en la lucha!” y “¡Pan, trabajo, justicia y libertad!” resonó en las calles del centro de Santiago. Eran las voces de centenares de obreros textiles de PANAL y PROMATEX en huelga, que coreaban ésta y otras consignas, repudiando el Plan Laboral de la dictadura y desafiando la represión policial ${ }^{21}$.

Este cambio sustantivo en la construcción socioeconómica tuvo claridad mediana entre los intelectuales pero no entre los sectores políticos, sobre todo entre los de izquierda que, bajo sus antiguas formas, creyeron ver en la crisis una oportunidad de sumar fuerzas para conseguir un objetivo puramente político como fue el derrocamiento de la Junta militar. Lo más grave fue la regresión en lo social y político, pues la redistribución del ingreso nacional en favor de los empresarios y el capital financiero, por consiguiente la reducción del gasto público del Estado, hizo caer los salarios y el poder de compra en un marco político de absoluta falta de libertad, generando tensiones potenciadoras de violencia.

Pese a lo anterior, entre la izquierda radicalizada la estrategia de guerra popular llevó a dar importancia a estos aspectos, haciendo de las nuevas condiciones económicas y sociales en las que se desenvolvía la vida de los sectores populares parte de la crítica más profunda al régimen, encontrando en estos cambios estructurales los puntos sobre los cuales discutir de cara a las clases populares las características de aquellas transformaciones.

El movimiento de pobladores, de fuerte impronta en las grandes ciudades del país, también significó una punta de lanza en esta reactivación. Las protestas nacionales vienen precedidas de la prácticamente nula política de inversión social en las poblaciones, además de las crisis económicas arrastradas hasta el momento. La organización y representación popular se anuló, pues no se permitió el funcionamiento de las juntas de vecinos, sumando a ello la fuerte represión sufrida desde el momento mismo del golpe militar.

Panfletos clandestinos del Frente de Resistencia Poblacional, por otra parte, convocan a los pobladores a realizar marchas, actos de protesta y toma de policlínicos y consultorios, para impedir la privatización del Servicio Nacional de Salud...22.

Los temas vinculados a la situación social de los pobladores de las grandes ciudades están en las causas de la movilización social, pero también en los argumentos del uso de mecanismos de violencia política. Surgen en torno a estos problemas múltiples organizaciones que organizan al mundo poblacional. La más importante del período, aunque no la única, es COAPO, Coordinadora de Agrupaciones Poblacionales, fundada en 1980 y vinculada a la resistencia y el $\mathrm{MIR}^{23}$.

\footnotetext{
${ }^{20}$ Artículo 12 del Código del Trabajo de 1979.

${ }^{21}$ El Rebelde, No 168 , noviembre de 1980, p. 2. Guillaudat y Mouterde señalan que ésta es la primera huelga que volcó a sus trabajadores fuera del recinto de la empresa, desafiando la prohibición de reunión y provocando la solidaridad de múltiples sectores.

${ }^{2}$ AIR, junio de 1980 , p. 2.

${ }^{23}$ La prensa mirista relata muchos sucesos de tomas de terrenos para el período, además del surgimiento de "ollas comunes" en torno a estas tomas, los desalojos y desórdenes en la vía pública por estos hechos son parte de los efectos de la nueva economía, mediada por su cara política en los conflictos.
}

Revista de Historia, año 17, vol. 17(2), 2007, pp. 53-69 
Ya sea en el sector salud u otro, las motivaciones de la Resistencia se encontraban fuertemente centradas en el desmantelamiento de las preocupaciones sociales por parte del gobierno, siendo las consignas que se estiman más relevantes para impulsar movilizaciones y actos de protesta.

En ese marco es que las acciones de violencia muchas veces fueron parte de las movilizaciones de los chilenos que decidieron protestar frente al estado de la situación económica y social. Es en este punto que se logra un vaso comunicante después de varios años, entre la izquierda radical, partidaria del uso de la violencia política y los primeros atisbos de movimiento social antidictatorial.

La resistencia tiene en la defensa del Estado desarrollista y protector un elemento que la acerca a la construcción básica del movimiento social de carácter popular en Chile. El diálogo que este movimiento había logrado fundar y desenvolver con ese Estado durante gran parte del siglo veinte.

Pero los alcances concretos de la crisis que desata la descomposición del Estado desarrollista y protector trae consigo un panorama que será consistente en el tiempo. Aún así, esta instalación refundada tiene en 1975 una fecha de nacimiento y un contexto histórico claramente reconocible. Para Chile esto se consolida a comienzos de la década del ochenta, en plena dictadura militar.

...se intensificó el proceso de precarización del trabajo asumiendo las formas, entre otras, de menor estabilidad laboral, reemplazo del empleo permanente por trabajo a tiempo parcial, así como la creciente subcontratación de la mano de obra que caracterizan el funcionamiento actual del mercado del trabajo ${ }^{24}$.

La política económica de shock llevó a la reducción del ingreso, el desempleo y la contracción del mercado interno, gatillando un descontento social creciente que sólo logra ser contenido por el estado de excepción. Finalmente, se cumple con la estrategia del régimen, al instalarse una reestructuración del capitalismo chileno, avalado por un marco legal acorde a las necesidades de este nuevo modelo social y económico.

\section{DERECHOS HUMANOS}

Los organismos de Derechos Humanos fueron los que comenzaron a agrupar a los militantes del incipiente movimiento social antidictatorial. Cada uno en su particular radio de acción considera una de las preocupaciones centrales que provoca el régimen militar entre la izquierda chilena. Preocupaciones que serán traspasadas con el tiempo a la agenda política del país, marcando el devenir de uno de los problemas que enfrentarán gobierno y oposición con miras a la llamada transición a la democracia.

En el ámbito de la lucha por los Derechos Humanos, son los grupos vinculados a distintas iglesias cristianas quienes comienzan a desarrollar acciones a poco de iniciada la dictadura. En 1973, después del golpe de Estado se fundó el Comité de Cooperación para la Paz en Chile, COPACHI, disuelta por presión del gobierno. En 1976 se convierte en la Fundación de Ayuda Social de las Iglesias Cristianas, FASIC. La tarea de estos organismos se concentraba en la prestación de servicios a las víctimas de violaciones a los Derechos Humanos.

La Vicaría de la Solidaridad comienza a trabajar desde 1976. Dependiente de la Iglesia Católica Romana se define en esta misma línea, aunque por el alcance de esta manifestación religiosa en Chile, tiene mayor amplitud en el tipo de prestaciones que establece. Sus funciones son diversas.

En la vicaría se realizan labores de investigación y análisis, existe un centro de documentación, información, publicaciones...La función de denuncia pública es indirecta, en la medida en que los acuciosos informes del cuerpo de abogados y asistentes sociales a los tribunales sirven de plataforma para la discusión de las tendencias y modalidades con que los servicios de seguridad cometen sus violaciones de los Derechos Humanos ${ }^{25}$.

Aspecto aparte es el desarrollo de las agrupaciones de familiares de las víctimas de la represión, conformadas por los parientes, mayoritariamente mujeres. Hicieron de la denuncia su principal actividad. Desde el terreno testimonial conformaron una protesta investida de denuncia moral sobre el régimen. Primero, la agru-

\footnotetext{
${ }^{24}$ Infante, Ricardo. "Mercado de trabajo y deuda social en los 80". PREALC-OIT, Programa mundial del empleo. Organización Internacional del Trabajo, $\mathrm{N}^{\circ} 35$, Santiago,1991, p. 8.

${ }^{25}$ Vidal, Hernán. El movimiento contra la tortura Sebastián Acevedo. Derechos humanos y la producción de símbolos nacionales bajo el fascismo chileno, 2002, p. 64.
} 
pación de familiares de presos políticos y luego la de detenidos desaparecidos. Esta última logra mayor estructura e impacto público con su accionar.

Hacia 1978 se constituye el Comité Pro Retorno de Exiliados. Se funda una nueva línea en la defensa de los Derechos Humanos. En 1980 se amplía el radio de acción con la fundación de la Agrupación de Familiares de Relegados. Todas estas organizaciones colaboran en los aspectos relativos a la denuncia de la situación de los Derechos Humanos en Chile.

Otra línea de organismos en el ámbito de los Derechos Humanos se constituye en torno a la reflexión del estado de la democracia y sus desencuentros en el Chile de esos años. En ella se inscriben la Academia de Humanismo Cristiano y el Servicio Paz y Justicia, SERPAJ, además de la Comisión Chilena de Derechos Humanos.

Hacia 1980 encontramos conformado un amplio espectro de organizaciones y personas movilizadas en torno a las problemáticas de los Derechos Humanos en Chile. En este marco es que surge el Comité de Defensa de los Derechos del Pueblo, CODEPU. Este organismo construye un concepto de lucha por los Derechos Humanos vinculado a lo político, particularmente a la promoción de los derechos políticos ciudadanos entre los más reprimidos social y políticamente, los sectores populares.

La definición del CODEPU corresponde al modelo que la Resistencia prefirió para enfrentar la lucha por los Derechos Humanos, vinculada a los sectores sociales movilizados contra la dictadura. Aliado a los grupos políticos tuvo activa participación en la articulación de acciones en el ámbito que le correspondió.

Cuando Fabiola Letelier pronunció el discurso central en representación del CODEPU, que preside, un grupo auténtico de dirigentes populares la respaldaba en la tribuna. Cada uno con la fuerza ganada en estos años por el organismo o sector social en cuyo nombre estaban ahí ${ }^{26}$.

En los años venideros CODEPU será ligado al Movimiento Democrático Popular, MDP. Activa agrupación política que desarrolló las protestas de mediados de los ochenta en las grandes urbes chilenas, donde también participó el MIR y la Resistencia como organizaciones políticas y milicianas, respectivamente. La fundación de CODEPU corresponde, entonces, a un avance en los niveles de activación de la política resistente en Chile.

Otro de los sectores donde se produjo la movilización social ligada a la Resistencia y el desarrollo de estrategia política de forma explícita fueron los jóvenes. Tanto la juventud universitaria como la poblacional se vieron involucradas de forma activa, constituyendo el grueso de los movilizados contra el régimen de facto.

La protesta masiva de estos jóvenes es, ante todo, una novedad en la historia política chilena, en la que el movimiento obrero y las clases medias -entre las que se encuentran los estudiantes universitarioshabían significado las acciones opositoras más significativas ${ }^{27}$.

Sin embargo, los asuntos ligados a los Derechos Humanos tendrían todavía algunos eventos que molestarían no sólo a la izquierda, sino a la oposición en su conjunto y que la Resistencia recogería para señalar la barbarie que en asuntos de represión se podía esperar del régimen.

No es preciso hilar muy fino para encontrar los motivos políticos que hay detrás del asesinato del presidente de la Asociación Nacional de Empleados Fiscales, Tucapel Jiménez. El viejo dirigente gremial había llamado días antes a constituir un amplio frente de trabajadores contra la política económica... ${ }^{28}$.

Los organismos de Derechos Humanos hacia 1982 todavía tienen mucho camino que recorrer y se enfrentarán a una constante actividad, no sólo por la represión a los militantes de partidos de izquierda, sino a quienes intentarán levantar movilizaciones que entorpezcan el derrotero prefijado por la facción triunfante en el bando gobernante.

\footnotetext{
${ }^{26}$ AIR, diciembre de 1983, p.1. En el acto de aniversario que se informa se contaban representados AD-MAPU, APD, UNED, CCT, COSP, COAPO, ATC y CODEM.

${ }^{27}$ Weinstein, José. Los jóvenes pobladores en las protestas nacionales (1983-1984), 1989, p. 6.

${ }^{28}$ AIR, abril de 1982 , p. 1.
}

Revista de Historia, año 17, vol. 17(2), 2007, pp. 53-69 


\section{MOVILIZACION SOCIAL, VIOLENCIA POLITICA Y RESISTENCIA}

Dentro de este análisis es lógico que haya surgido el fenómeno de la violencia política contra objetivos claramente representativos del sistema político y social imperante. Martínez et al. señalan que en el caso chileno los actos de violencia son en un $75 \%$ de expresión política organizada ${ }^{29}$. Lo que no está suficientemente aclarado en este asunto, es si esta violencia política organizada tiene influencia en las decisiones que llevarán el proceso por las diversas vías que se presentan en el conflicto. En este sentido es fundamental acotar las características y los pasos que dio la lucha contra la dictadura, es decir, cómo se recibían los actos de violencia política entre la dirigencia política y las organizaciones sociales encargadas de conducir el proceso.

Nos encontramos con una primera idea. La violencia es usada como mediación política y en este sentido, representa un mecanismo anómalo de negociación política. La lucha pública por buscar salida al "extremismo" formará parte del debate político dirigencial en el Chile de fines de los ochenta. Con la descripción que hacemos sólo intentamos poner a la violencia política como una referencia a la hora de formular la discusión política y tomar las decisiones que harán de Chile el país que es.

A fines de la década de los setenta, los intelectuales de izquierda comienzan a tomar posiciones más cercanas al centro político y a posturas ideológicas que podríamos definir como socialdemócratas. Este giro se genera en virtud de los errores de la izquierda chilena y latinoamericana, además de los retrocesos de los socialismos europeos. Salvedad se debe hacer en la situación centroamericana, donde la Resistencia chilena refuerza sus posiciones y busca soporte moral para su estrategia.

Será la propia movilización social y política la que haga redefinir las posturas de la izquierda chilena, retrayéndola al análisis de la situación interna y desde ahí configurando las posibilidades de conflicto con el régimen. Surgen entonces diversidades en cuanto al proyecto que generará mayor éxito para democratizar el país.

En definitiva, es en los sectores populares donde se centrará la participación de la Resistencia, a través de múltiples actos de violencia de baja intensidad ligados a las movilizaciones sociales donde se articula una forma de protesta radicalizada, convocada al posicionamiento político de los pobres urbanos.

Señalamos que con este accionar las Milicias de la Resistencia Popular apoyan militarmente las manifestaciones de repudio masivo a la dictadura, las marchas, mitines y ollas comunes. Acciones que van demostrando que el pueblo ya ha tomado la firme decisión de no tolerar más el hambre, la cesantía y la opresión.... ${ }^{30}$.

La izquierda radical ha diseñado ya desde hace tiempo una forma de encarar estos desafíos. Es en construcciones como estas donde se apostará la movilización social fuertemente politizada y convocante, en función de la lucha de clases agudizada por el propio régimen de facto a través de su política social y económica.

Para entender mejor el fenómeno estimamos que se pueden establecer dos tipos de violencia política para el período. Por una parte la violencia política de alta intensidad, ejercida preferentemente por la Fuerza Central del MIR, la cual se puede definir primero por el resultado de muerte con que concluye, esto producto de la actividad guerrillera desarrollada, más que por la búsqueda específica de la muerte. Esto se verifica tanto para los ataques a las personas como para los falsos enfrentamientos, aunque también se puede observar en los asaltos bancarios; estos últimos comparten con los primeros el alto impacto público que generan, haciéndolos parte de esta alta intensidad de violencia política.

Un segundo tipo de violencia política es la de baja intensidad, desarrollada generalmente por las Milicias de Resistencia Popular. Podemos llamarla de baja intensidad, pues si bien es mucho más llamativa que la anterior, prácticamente no deja resultado de muerte. Además es obviada permanentemente por los medios de comunicación oficiales. Por otra parte, es la que fructifica en el desarrollo de experiencias de lucha social y preparación de cuadros paramilitares para la estructura del MIR, por tanto, el que sea de baja intensidad no significa que sea menos importante.

\footnotetext{
${ }^{29}$ Martínez, Javier, Eugenio Tironi, Eugenia Weinstein. Personas y escenarios en la violencia colectiva. 1990, p. 28.

${ }^{30}$ El Rebelde, No 192, noviembre de 1982, p. 11. Esta declaración está inscrita en el desarrollo de diversas acciones de violencia para apoyar las marchas del hambre que se desarrollaron a fines de 1982 en diversas ciudades de Chile, ésta corresponde a una realizada en Viña del Mar.
} 


\section{EL MOVIMIENTO DE RESISTENCIA POPULAR}

\section{Definiciones y características del Movimiento de Resistencia Popular}

En este período, el mirismo alentó la creación del Movimiento de Resistencia Popular. Este organismo encabezó durante largo tiempo gran parte de las acciones de violencia política de baja intensidad, particularmente en las grandes urbes del país. El MRP se encuentra conectado al movimiento político social de forma estrecha. Por otra parte, las acciones de mayor envergadura eran realizadas por la llamada "Fuerza Central" del MIR. Ambas instancias son clandestinas y fueron las que sostuvieron la violencia como arma política durante buena parte de los años que cubre la dictadura.

Según documentos internos del MIR, el Movimiento de Resistencia Popular se articula desde el mismo momento del golpe militar y a pesar de los duros reveses sufridos, logra definir aspectos tácticos y estratégicos. En conjunto con otras fuerzas políticas se levantan plataformas de lucha. Se hace necesario entonces historiar, entre otros, los Comités de Resistencia y las Milicias de Autodefensa, vinculados a las organizaciones del movimiento social y político que emergen como la primera forma de oposición al régimen de facto.

El MRP tiene antecedentes de constitución real ya desde 1974, producto de la dura represión a los sectores proclives a la izquierda que se manifestaban en huelgas y conflictos locales. En este contexto se agrupan cuadros militantes de diversos referentes e incluso, sin partido. Este embrión de Resistencia se dedicó a estructurar lo que sería la oposición a la dictadura desde los vestigios de la organización social, gremial y estudiantil que se armaba para el actuar solidariamente frente a problemas económicos o brindar protección a las víctimas de la represión.

El Movimiento de Resistencia Popular viene a proponerse como objetivo la acumulación de fuerzas políticas y sociales en los más diversos ámbitos. Su finalidad fue constituirse en una referencia no burguesa de lucha contra la dictadura militar. Esta característica hace concebir al movimiento mencionado como amplio y clasista, en el entendido de incorporar a todos los elementos provenientes del campo popular que deseen adscribirse a esta política de Resistencia.

Producida la muerte del secretario general del MIR, Miguel Enríquez, y tras el golpe represivo de Malloco que desarticula la dirección del MIR, el proceso de constitución de Resistencia se ve fuertemente afectado. Gran parte de la estructura política y militar del partido fue diezmada ${ }^{31}$. Con ello la composición del Movimiento de Resistencia es dificultado, pero no interrumpido. De hecho recae en Hernán Aguiló y un grupo ligado a este ex dirigente del FTR la tarea de reconstruir el partido y seguir su línea estratégica. En este sentido, el MRP es fundamental para el momento.

Obviamente quedaba un partido pequeñísimo, prácticamente sin estructuras, con mínimos vínculos con el movimiento de masas, con pocos Comités de Resistencia, centrado en las actividades internas y la propaganda clandestina. Otros grupos pequeños se mantuvieron desconectados, realizando por propia iniciativa un trabajo partidario ${ }^{32}$.

Surge la pregunta acerca de si es el MRP un movimiento en sí mismo o si es sólo una política o estrategia del MIR para el período. Si es así ¿Cuáles son los objetivos de esta política? ¿Cómo se maneja el interior del partido en términos orgánicos y decisionales? ¿Qué principios guían el desarrollo de esta constitución MRP? El devenir histórico de este agenciamiento aclara la centralidad de la constitución que estudiamos.

Es en este período que surge la construcción que llamamos movimiento político y social antidictatorial, nutrido de las más diversas motivaciones e influido por distintos factores. En todo caso cabe preguntarse si el MRP tiene algún rol en el surgimiento y desarrollo de este fenómeno; si es así para qué, cómo lo hace, en cuáles espacios, con cuáles herramientas.

El Movimiento de Resistencia Popular nace en el contexto de una propuesta mirista al conjunto de la izquierda chilena, con el objetivo de organizar a las bases de militantes que no se encuentran movilizadas, en torno a la idea de destituir al gobierno de facto. Esta propuesta es llamada Frente Político de la Resistencia y está dirigido a un amplio abanico, desde el propio MIR y hasta la izquierda del PDC.

\footnotetext{
${ }^{31}$ Cavallo, A., et al. La historia oculta del Régimen militar. Memoria de una época. Santiago, 1997. Proponen esta definición bastante aceptada ya entre los analistas y estudiosos del tema.

${ }^{32}$ Cristián Pérez. Historia del MIR. "Si quieren guerra, guerra tendrán..." Estudios Públicos, Santiago, N 91, 1993. p. 22.
}

Revista de Historia, año 17, vol. 17(2), 2007, pp. 53-69 
Sin embargo, la propuesta no tiene la acogida que se espera y se opta por la estructuración del MRP con la militancia del partido rojo y negro y los independientes que se quieran sumar a esta táctica política. En el período de su articulación este movimiento de Resistencia lucha contra las referencias partidarias de izquierda en torno a que la Resistencia no es un espacio de representación partidaria, sino una movilización masiva y organizada de los sectores populares opuestos al régimen de la Junta militar.

Gran parte de esas diferencias se traslucían en las diversas nomenclaturas utilizadas para llamar a los distintos factores y articulaciones que bregaban por organizar esta Resistencia. El MRP intenta explicar su posición en torno a la amplitud y el clasismo de su propuesta y estima que otras formas de construir oposición son concebidas con criterio de sectarismo e independencia de la participación del pueblo.

Si bien esta discordancia ocurría entre las cúpulas partidarias, en la base social la Resistencia se empeña por conquistar y recibir a todos quienes cumplan con los requisitos para conformar los comités de resistencia, sean o no militantes del MIR. Por ser espacios de funciones específicas y pragmáticas, no fue extraño encontrar en estas estructuras a militantes de partidos de la Unidad Popular que prefirieron una política de acción directa contra la dictadura a esperar las definiciones de sus partidos.

También hay masones y radicales. Mire, en la Resistencia a nadie se le pregunta de qué partido político es, ni qué creencias filosóficas o religiosas tiene. Sólo se le pide que sea consecuente con la lucha democrática independiente de nuestro pueblo y que luche activamente contra la dictadura ${ }^{33}$.

La Resistencia se considera un agenciamiento político pero dentro de una movilización general del pueblo en pro de una causa política que desarrolla el conflicto en los marcos de los debates socioculturales en los que se define políticamente una sociedad, es decir, en la inclusividad del proyecto de nación.

Destruido el movimiento social por la dictadura, la resistencia tendrá el rol de producir la recomposición de éste, pero en un contexto de clandestinidad, ocultamiento y actividades alternativas a las formas de participación oficial.

Por último y en la perspectiva anterior, consideramos que el Movimiento de Resistencia Popular influyó de forma importante en la génesis y desarrollo del movimiento social antidictatorial, pero que dejó su participación en un ámbito donde no tuvo mucho conocimiento de sus efectos y resultantes.

\section{Fuerza Central}

En el contexto del Plan 78 se constituye en Chile la Fuerza Central. Estaba compuesta por grupos operativos de alta preparación paramilitar, destinados a reforzar las acciones de las milicias de autodefensa y generar condiciones para las acciones guerrilleras que contemplaba el Plan. En diciembre de 1979 se produce el asalto al supermercado AGAS, marcando el inicio de un período de violencia política que provocaría una nueva etapa en la política chilena.

La Fuerza Central se constituye tanto con elementos provenientes de la Operación Retorno como con militantes que habían permanecido en el país luego del Golpe de Estado. Pretendía conformar el núcleo del futuro Ejército Revolucionario, según la estrategia de Guerra Popular Prolongada. Estos grupos se diferencian de las milicias de autodefensa en el armamento y preparación de combate que tienen sus miembros, por lo tanto, están preparados para acciones de mayor envergadura.

Estas acciones abarcaron particularmente los asaltos a bancos y a entidades con fuerte flujo de dinero en efectivo; enfrentamientos con fuerzas de seguridad, orden público y represión política y ajusticiamientos o muertes a responsables directos de violaciones a derechos humanos, así como a representantes del régimen militar. Además de estos actos de violencia política, la Fuerza Central participó en otros hechos anexos a los del tipo señalado, como coadyuvantes a la consecución de los objetivos que definieron en su momento.

Desde 1979 la Fuerza Central constituyó e hizo operar los denominados "grupos centralizados de combate". Estos grupos conforman las unidades operativas en el combate contra la dictadura militar y los elementos que la componen se encuentran profesionalizados, es decir, se dedican íntegramente al trabajo paramilitar. Además permanecen en la clandestinidad y trabajan en una estructura jerárquica y compartimentada en cuanto a las decisiones y la información que manejan ${ }^{34}$.

${ }^{33}$ El Rebelde, $\mathrm{N}^{\circ} 163$, p. 9. Esta cita obedece a una entrevista hecha a Andrés Pascal Allende, secretario general del MIR.

${ }^{34}$ Cristián Pérez: Op. cit; pp. 35-44, desarrolla un pormenorizado análisis de las características y desarrollo de la Fuerza Central en el período 1979-1983. 
Al estudiar las acciones de la Fuerza Central queda en evidencia que sus objetivos más importantes se encuentran relacionados con el ataque de la estructura económica y política de la dictadura; tanto los ataques a personeros del gobierno y afines, como los asaltos bancarios así nos lo demuestran.

Durante 1980 los grupos centralizados de batalla lograron poner en jaque a los aparatos de la política represiva del gobierno. La Fuerza Central cumplió un rol importante en la fundación de una movilización del pueblo contra el régimen de facto y más allá del aniquilamiento que sufrió, podemos considerar que logró abrir flancos por los cuales el MIR pudo defender sus posiciones y volcarse al desarrollo de su estrategia, particularmente en las ciudades.

La Fuerza Central fue la estructura mirista encargada de llevar el peso de la guerra popular contra la dictadura. 1980 fue el año en que se desarrollaron las batallas más crudas de esta guerra y que costaría la vida de valiosos militantes del partido, así como bajas destacadas de los aparatos de seguridad y represión. Todo esto se enmarcó en la definición de esas estructuras del régimen militar, cuestión que definiría el destino de la Fuerza Central y de la Resistencia.

Se iniciaba una fase distinta en los aparatos de seguridad. Era necesario actuar en varios niveles: golpear con fuerza la resistencia armada, atemorizar a las renacientes organizaciones sociales, impedir la exteriorización del descontento. La combinación de ambas estrategias llevaría a una espiral de muertes, de uno y otro bando... ${ }^{35}$.

Por último, la característica fundamental que llevó a perseguir tan duramente a la Fuerza Central estuvo dada por su capacidad militar, lo cual quedó demostrado en la presión que sufrió la CNI en su momento, y por la necesidad de destruir los cuadros mejor preparados para que no se desarrollaran proyectos exitosos en el terreno de la lucha política y militar contra el régimen de facto.

Se debe comprender que la Fuerza Central actuaba como un aparato armado pero con una clara dirección e intención política. De allí que la supervivencia de la resistencia se explique en parte por la concepción diversa que se tenía de los mecanismos a través de los cuales actuaba la política del MIR en esos años.

\section{Milicias de la Resistencia Popular}

Los comités de Resistencia son estructuras que comenzaron a organizarse en los primeros tiempos de la dictadura y dieron pie para que el Movimiento de Resistencia Popular comenzara a tomar corporalidad. Se le consideró elemento fundamental y se organizó en torno a los cuadros de vanguardia de los partidos revolucionarios, eminentemente el MIR. Se debe comprender que en los primeros años posteriores al golpe de Estado de 1973, esta tarea se realizó con los pocos militantes que no sucumbieron a la política represiva del Estado, por lo tanto, el funcionamiento de estos comités está relativizado por la sobrevivencia que debían mantener estos cuadros políticos frente a la persecución de la que eran objeto.

El comité de Resistencia es la génesis de las milicias de autodefensa que cobrarán vida y protagonismo en el período posterior a 1978. Estos comités estructuraron una organización básica, actuaron en espacios muy localizados y tenían múltiples funciones, a diferencia de las milicias, que tenían diversidad en sus tareas. Los comités de Resistencia debían encargarse de la seguridad, la propaganda, del financiamiento, entre otras funciones.

Los Comités de Resistencia fueron concebidos como grupos de gran amplitud enfocados a tareas específicas. Primaba la idea de generar condiciones subjetivas acerca del régimen militar y masificar la presencia de la Resistencia en el país.

La unidad de todos los militantes de izquierda y de todo demócrata consecuente en los frentes y la creación de cientos de nuevos comités de resistencia antidictatoriales, es otra de las nuevas tareas para 1980, la unidad y organización de nuevos comités de resistencia ayudará enormemente a consolidar la resistencia de masas y la resistencia militar contra la dictadura ${ }^{36}$.

\footnotetext{
${ }^{35}$ Cavallo, A. et al. Op. cit. p. 295.

${ }^{36}$ El Rebelde, $N^{\circ} 157$. p. 4.
} 
Junto a los Comités de Resistencia se generan otras estructuras dentro del Movimiento de Resistencia Popular, esta vez dirigidos a la política paramilitar que el MIR delinea para el período que le toca enfrentar. Las Milicias de Autodefensa son parte fundamental de la estrategia seguida por el MIR. Estos grupos fueron organizados para combatir en espacios locales muy específicos y utilizaron violencia de baja intensidad en su accionar.

La milicia se define particularmente en las siguientes características:

- Sus miembros no se dedican solamente a ella, siguen en su lugar de trabajo o estudio.

- Las milicias subsisten por la autogestión de los recursos que necesita para su labor.

- Actúa en el mismo lugar de donde provienen los milicianos.

- Desarrolla sus acciones de violencia política en virtud de la coyuntura local.

- Presta apoyo al trabajo militar de la Resistencia.

Estas milicias se configuran en grupos reducidos de personas (4 6́ 5) que eran reclutados en lugares como el barrio, el lugar de trabajo o estudio, previa observación y consideración del grupo. La milicia tiene carácter horizontal y sólo cuenta con el cargo de jefe, quien tiene responsabilidades netamente operativas, pues las decisiones se dialogan en reuniones del grupo. De todas formas, la Milicia depende de un mando superior, formando parte de una estructura paramilitar mayor, lo que no impide que defina objetivos y acciones desde su propio espacio de decisión. "La gran cualidad o la gracia que tienen las milicias es que pueden actuar en la lucha callejera, en las tomas o manifestaciones, organizando y conduciendo la defensa popular frente a la represión" ${ }^{37}$.

Las milicias tienen la base social como su apoyo fundamental. En esta premisa, se organizan tareas como el apertrechamiento y el reclutamiento en el barrio o lugar de trabajo o estudio. Por otra parte, se definen diversos tipos de milicias de apoyo, diferenciadas por su función en torno a las acciones de la Resistencia; así, existieron milicias de información, de sanidad, de agitación y propaganda, de transporte y de seguridad. Estas milicias de apoyo posibilitan que distintas personas participen de las actividades de la Resistencia, configurando un movimiento en torno a esa Resistencia.

Los milicianos tienen una preparación militar además de la política. Esta preparación está basada en aspectos básicos de la lucha urbana, es decir, se instruye en táctica para el territorio específico, explosivos y el desarrollo físico de los milicianos. Cabe aclarar que si bien se definió que las milicias se instalaran en espacios rurales y urbanos por parte de la estrategia, estos grupos se constituyeron mayoritariamente en las grandes ciudades del país. En la revisión de prensa no encontramos prácticamente nada de su accionar en zonas rurales, sin embargo, debe anotarse actividad en torno a acciones en el campo, como rotura de matrices de riego y abigeato.

La instrucción política tenía por misión hacer comprender a los milicianos el estado de la situación política del país, el saber por qué se emprende esa lucha; debía conocer la estrategia de la Resistencia así como los objetivos que perseguía; entender los propósitos e ideas de la Milicia de Autodefensa. En este sentido, la raíz política se encuentra en el específico camino de la derrota de la dictadura.

Toda la instrucción está cruzada por valores morales de ineludible mención; se repite la necesidad de la disciplina, la conciencia política, la lealtad al grupo y la consecuencia. Las milicias contaban con un código de honor que resumía estos aspectos, además de un himno del miliciano.

Tema fundamental de los grupos milicianos era el de la clandestinidad tanto de la pertenencia de sus miembros como de su acción específica. Si bien esto parece de perogrullo, en su momento definía la posibilidad de encarar la desaparición, la tortura o la pena de extrañamiento, cuestión de la que los milicianos tuvieron conciencia absoluta. Por ello insistían en medidas de seguridad como esconder las armas que poseían, dejándolas fuera de los posibles allanamientos.

También existían métodos específicos para el reclutamiento de los milicianos. Así como no se podía hablar libremente con otros milicianos de temas políticos o paramilitares. Fundamental era el no reconocimiento de la identidad durante las acciones del grupo miliciano, por esto se utilizaban pañuelos o pasamontañas, además de actuar preferentemente de noche.

\footnotetext{
${ }^{37}$ Manual General de Preparación combativa, p. 8.
} 
El miliciano podía participar de movilizaciones de reivindicación social o política, pero debía participar como un manifestante, menos aún si se sospechaba que era reconocido por otros como parte de la Resistencia. No se permitía a los milicianos la realización de actos de violencia política en el desarrollo de estas actividades públicas.

Las razones que esgrimió la Resistencia para considerar la creación y desarrollo de las Milicias de Autodefensa parten por el estado político, social y económico del país. Desde ahí se construye un discurso político referido a los sectores más deprivados del país. Este arranque viene a situar a las milicias como una necesidad, como una respuesta frente a la ilegitimidad del interlocutor. El Mando Nacional de las Milicias señala:

En todos estos años hemos comprobado que las demandas en los tribunales, frente a los despidos, no solucionan el problema de la cesantía, que las cartitas a las autoridades ayudan, pero bien poco, que ante las peticiones que formulamos a los patrones, sólo recibimos la prepotencia...Todo esto ha ido demostrando que sólo el pueblo defiende al pueblo ${ }^{38}$.

Debido a este punto de partida que señala la ilegitimidad y la nula posibilidad de resultados por la mediación de las instituciones políticas, gran parte del trabajo realizado por las Milicias de Autodefensa tuvo que ver con acciones contra la política represiva del régimen. Esto implicó desarrollar mecanismos de inteligencia para hacer defensa de las movilizaciones populares, así como descubrir y hostigar a los afectos a la dictadura en los espacios locales.

Aquí se instalaron las acciones como los amedrentamientos a informantes de las agencias de seguridad del Estado, daño a la propiedad e inclusive el ajusticiamiento. Concebida como guerra sicológica, las acciones de este tipo iban destinadas a crear intranquilidad en el enemigo político, las llamadas telefónicas y cartas, así como los rayados y panfletos eran acciones preferidas para estos efectos.

En esta línea está la creación de brigadas que protegían las movilizaciones llevadas a cabo en el sector donde operaba la Milicia de Autodefensa. Esto consideraba desplegar personas que cuidaran los espacios de reunión, las movilizaciones y las marchas ante posibles ataques de civiles y agentes de seguridad que pudieran atacar al grupo de manifestantes. Se partía del hecho que los dirigentes sociales acepten esta seguridad, por tanto ellos conocen a los milicianos que ofrecen esta protección.

Las tareas más frecuentes y mejor desarrolladas por estos grupos eran las actividades de agitación y propaganda. Este ámbito se encontraba justificado por la falta de pluralismo de los medios de comunicación masiva. Para la Resistencia era necesario hacer conocer sus planteamientos frente a la situación política del país y divulgar sus acciones; para ello los milicianos encontraron variadas formas de expresión.

Dentro de las más recurridas estuvo el uso del panfleto y el rayado de muros. Se utilizaron lienzos, bombas parlantes y particularmente barricadas con mítines relámpago. Se debe agregar que existía un periódico de las Milicias de Autodefensa, "El Miliciano", usado como herramienta de propaganda en los espacios donde el grupo desarrollaba su acción política.

El área de mayor relevancia para el régimen, por el impacto que tenía en su discurso, era la de los sabotajes a diversos focos del aparato productivo y a la red de infraestructura del país. La dictadura comenzó su labor de gobierno definiéndola como la "reconstrucción nacional", cualquier acción de violencia contra esa tarea fue denostada, reforzando la diferencia entre los proyectos desde el hecho del daño material.

Acciones como el asalto a camiones repartidores y la distribución de sus productos entre la población más carenciada, fueron actos de sabotaje frecuentes realizados por grupos milicianos, aprovechados para hacer agitación política de los objetivos y las posiciones de la Resistencia. En las coyunturas como huelgas, ollas comunes o tomas también se recurría a estas acciones, estimando que era necesario para mantener la satisfacción de las necesidades fundamentales en medio de los conflictos.

Para las milicias era importante mostrar que había un país inseguro e intranquilo, donde el proyecto del régimen de facto estaría cuestionado por el amplio rechazo del pueblo a través de la Resistencia. En este aspecto fueron relevantes los cortes de luz por cadenas en el tendido eléctrico, la interrupción de las vías por miguelitos, destrucción de señalética, bombas cazabobos y bombas falsas, destrucción de propiedad fiscal y toma de microbuses.

\footnotetext{
${ }^{38}$ Manual Gencral de Preparación combativa, p.7.
}

Revista de Historia, año 17, vol. 17(2), 2007, pp. 53-69 
Aspecto relacionado con lo anterior es la recolección de armas de fuego a través del desarme de agentes de seguridad del Estado y de particulares; la expropiación de recursos para el trabajo de los grupos milicianos como mimeógrafos, dinero, medicamentos y diversos materiales para la lucha callejera.

La forma de relacionar la política mirista de movilización popular contra el régimen de facto pasó por un concepto verticalista del rol que le cabía a los manifestantes. De este modo, se privilegiaban las acciones agitativas en las poblaciones, sin considerar la construcción de organizaciones permanentes. Bajo esta modalidad, se perdía influencia rápidamente entre los sectores agitados por la militancia mirista.

Los milicianos bajo la conducción de los mandos zonales en provincias que responden a su vez al Mando Nacional son la fuerza naciente del ejército popular que hará posible, junto a la organización de la Resistencia Popular y el conjunto de las fuerzas democráticas y antidictatoriales, llevar adelante los anhelos libertarios del pueblo chileno ${ }^{39}$.

La Resistencia constituyó un eslabón estratégico dentro de la política de la izquierda radical, heredando gran parte de la experiencia y las corrientes ideológicas de su tiempo, se inscriben como reserva moral contra la política del terror generada por el régimen de facto; acudiendo a una ética del rigor y el orden estricto de la organización.

Estas instalaciones milicianas se ubicaron en y con el movimiento popular, en poblaciones y universidades, en las grandes ciudades como entidades de mayor relevancia. Se efectuaron desde la lógica de pensar que desde grupos cerrados y con mayor formación política se influía en orgánicas públicas y desde ahí se hacían conocidas las posturas del MIR para el conjunto de la población.

\section{BIBLIOGRAFIAS}

AIR, junio de 1980, mayo de 1981, abril de 1982, diciembre de 1983, mayo de 1991.

Cavallo, Ascanio. Manuel Salazar y Oscar Sepúlveda. 1997. La Historia oculta del Régimen militar. Memoria de una época. Grijalbo, Santiago.

Elter, Doris. 1999. Sistema de A.F.P. chileno. Injusticia de un modelo. LOM - Universitaria ARCIS, Santiago. Garretón, Manuel. 1990. "Del autoritarismo a la democracia política. ¿Una transición a reinventar?", Documentos de trabajo, FLACSO, Santiago, $\mathrm{N}^{\circ} 5$.

Guattari, Félix y Antonio Negri. 1999. Las verdades nómadas \& general intellect, poder constituyente, comunismo. Editorial Akal, Madrid.

Guillaudat, Patrick y Pierre Mouterde. 1998. Los movimientos sociales en Chile.1973-1993. LOM. Santiago. Illanes, María Angélica. 1994. "Marginalización y des-marginalización del movimiento popular". Proposiciones, Ediciones Sur, $\mathrm{N}^{\circ} 24$.

Infante, Ricardo. 1991. "Mercado de trabajo y deuda social en los 80", PREALC-OIT, Programa mundial del empleo. Organización Internacional del Trabajo, $\mathrm{N}^{\circ} 35$, Santiago.

Larraña, Enrique. 1999. La construcción de los movimientos sociales. Alianza Editorial.

Manual General de Preparación combativa. Sin pie de imprenta.

Martínez, Javier, Eugenio Tironi, Eugenia Weinstein. 1990. Personas y escenarios en la violencia colectiva. Meller, Patricio. 1998. Un siglo de economía política chilena (1890-1990), Andres Bello, Santiago.

Pérez, Cristián. Historia del MIR. "Si quieren guerra, guerra tendrán..." Estudios Públicos, Santiago. No 91. Pinto, Julio. "Movimiento social popular: ¿Hacia una barbarie con recuerdos?" Proposiciones, Ediciones Sur, $\mathrm{N}^{\circ} 24,1994$.

Rebelde (El). No $157, \mathrm{~N}^{\circ} 163, \mathrm{~N}^{\circ} 168,1980 ; \mathrm{N}^{\circ} 192,1982$.

Salazar, Gabriel y Julio Pinto. 1999, Historia contemporánea de Chile. Volumen I, LOM, Santiago.

Touraine, Alain. 1990. Movimientos sociales hoy. Barcelona, Hacer.

Valdivia, Verónica. 2003. El golpe después del golpe, Leigh vs. Pinochet. LOM.

Vidal, Hernán. 2002. El movimiento contra la tortura Sebastián Acevedo. Derechos Humanos y la producción de símbolos nacionales bajo el fascismo chileno. Mosquito Comunicaciones.

Weinstein, José. 1989. Los jóvenes pobladores en las protestas nacionales (1983-1984). Santiago, CIDE.

Zamorano, Raúl. 1999. "Dilemas políticos sobre los movimientos sociales. El accionar colectivo de los sectores populares en el Chile de los años ochenta", Revista mexicana de Sociología, México D.F, Vol. $61, N^{\circ} 3$.

${ }^{39}$ AIR, Mayo de 1981, p. 2. 